\title{
Counter-directional latitudinal clines of size at upstream migration between two adjacent water bodies in a Japanese amphidromous fish
}

\author{
Iki Murase ${ }^{1}$, Tatsuya Kawakami ${ }^{2}$, Takahiro Irie $^{3, *}$, Kei'ichiro Iguchi $^{1}$ \\ ${ }^{1}$ Graduate school of Fisheries and Environmental Sciences, Nagasaki University, Bunkyo-machi, Nagasaki 852-8521, Japan \\ ${ }^{2}$ International Coastal Research Center, Atmosphere and Ocean Research Institute, The University of Tokyo, Akahama, \\ Ohtsuchi, Iwate 028-1102, Japan \\ ${ }^{3}$ Atmosphere and Ocean Research Institute, The University of Tokyo, Kashiwanoha, Kashiwa, Chiba 277-8564, Japan
}

\begin{abstract}
Latitudinal clines of phenotypic traits have been repeatedly reported in various species. The present study, however, is the first to demonstrate that intra-specific latitudinal clines in body size can be reversed in geographically distinct areas. Life-history traits in the early ontogenetic stage of the amphidromous fish ayu Plecoglossus altivelis altivelis were compared across 2 sides of the Japanese Archipelago. We analyzed otoliths from 231 individuals collected from 23 rivers (11 and 12 rivers flowing into the Sea of Japan and Pacific Ocean, respectively) to determine age at upstream migration and growth rate. As widely observed across ectotherms, fish from higher latitudes displayed relatively slow growth. Slopes of these clines, however, differed between the 2 water bodies, resulting in counter-directional latitudinal clines of size at upstream migration. A positive latitudinal cline in body size in populations and negative latitudinal gradient in seawater temperature from the Pacific side was consistent with the temperature-size rule. In contrast, a negative latitudinal cline of migration size was found in the Sea of Japan. This arose partly from unexpectedly fast growth of fish in the southern Sea of Japan, likely achieved by local migration into more suitable thermal microhabitats during overwintering. Our findings highlight how phylogenetically prevailing patterns at the macrogeographic scale can be masked by mechanisms specific to particular taxa, such as life-history responses to thermal heterogeneities on a smaller scale.
\end{abstract}

KEY WORDS: Amphidromous fish · Ayu $\cdot$ Geographic variation $\cdot$ Growth trajectory $\cdot$ Marine stage $\cdot$ Temperature

\section{INTRODUCTION}

The quantitative study of geographic variation in life-history schedules is an essential first step in understanding how organisms cope with and adapt to both spatial heterogeneity and temporal variability of environmental conditions. Particularly for fishery target species experiencing climate change, such basic biological information is imperative for informed decision making in stock management and

\footnotetext{
${ }^{*}$ Corresponding author: irie@aori.u-tokyo.ac.jp
}

conservation. In recent years, there has been growing evidence regarding intraspecific geographic variation in morphological and life-history traits in fish. For example, latitudinal variation is known in body size (Belk \& Houston 2002), vertebral number (Billerbeck et al. 1997, McDowall 2008), the number of scales along the lateral line (Nishida \& Sawashi 1987), fin length (Kawajiri \& Yamahira 2011), growth rates (Conover \& Present 1990, Jensen et al. 2000, Yamahira et al. 2007), growth trajectory with matura-

() The authors 2019. Open Access under Creative Commons by Attribution Licence. Use, distribution and reproduction are unrestricted. Authors and original publication must be credited. 
tion size/age (Trip et al. 2014), the proportion of matured individuals at age 1+ (Valiente et al. 2005), age at spawning (Neuheimer \& MacKenzie 2014), and egg size (Iguchi 1993). Body size and other sizerelated traits often positively depend on latitude, as these are suspected to be mediated by temperature in accordance with the temperature-size rule (Atkinson 1994), which posits phylogenetically widespread plasticity whereby individuals at the same developmental stage grown at colder temperatures are larger than those at warmer temperatures.

Theoretically, a phenotypic trait will not necessarily exhibit identical latitudinal clines among different seas, possibly because latitudinal gradients of relevant environmental factors may differ between water bodies. Another reason for the differences in latitudinal clines could be geographic variations in genotypes responsible for the focal traits. A comparison of phenotypic latitudinal clines between different water bodies would be helpful in disentangling the interrelated factors behind the observed phenotypic patterns. A good example is the study performed by Metcalfe \& Thorpe (1990), where latitudinal clines of age at smoltification (i.e. migration from freshwater to saltwater) in Atlantic salmon Salmo salar were compared among 3 regions (the Atlantic coast of Canada, Atlantic European coasts, and Baltic/White Sea coasts). The age at smoltification consistently increased with increasing latitude, but the slope differed among the 3 coasts. The authors successfully estimated that a major part of the phenotypic variance was explained by the variability of growth opportunities among individuals, being ultimately ascribable to temperature and day length. Another example has been reported from the European eel Anguilla anguilla in the North Atlantic, in which positive latitudinal clines of body size at maturity were found (Vøllestad 1992); however, in this case, a relationship with longitude was also found.

The islands of Japan represent a strong model system for comparing phenotypic clines in marine species because the archipelago encompasses a broad range in latitudes, and marine environmental conditions are notably different between the eastern and western sides. Off the coast of the Pacific Ocean (eastern side of the archipelago), the warm, saline, oligotrophic waters of the Kuroshio Current move northward from the tropics and, at $\sim 38^{\circ} \mathrm{N}$, collide with the nutrient-rich Oyashio Current flowing down from the Arctic. This confluence of warm and cool waters creates a large thermal gradient which contrasts with the lack of a thermal gradient found in the Sea of Japan (western side of the archipelago), where the less oligotrophic Tsushima Warm Current (a branch of the Kuroshio Current) is dominant across all latitudes. These differences result in seasonally and latitudinally distinct thermal regimes between the 2 water bodies (Fig. S1 in the Supplement at www.int-res.com/articles/suppl/m624p143_supp.pdf).

The ayu Plecoglossus altivelis altivelis in Japan is mainly distributed from southwestern Hokkaido to Kagoshima. This species is one of the main fishery targets in Japanese rivers, and young individuals raised in hatcheries are commonly released into wild riverine populations for stock management (Katano et al. 2015). The life history of this species is amphidromous in the sense that newly hatched larvae are swept from the natal river to the sea and, after metamorphosis to the juvenile stage, migrate back to the river for further growth and reproduction (see Fig. 1). The ayu forms exclusive foraging territories, which has long provided a good model system in behavioral ecology (Katano \& Iguchi 1996). This species is also potentially suitable for examining latitudinal variation in phenotypic traits because this fish has no long-distance migration and remains in the vicinity of its natal river throughout its life. From the viewpoint of evolutionary ecology, variation in phenotypic traits associated with life-history transitions, such as age at smoltification in the Atlantic salmon (Metcalfe \& Thorpe 1990) or size at maturity in the European eel (Vøllestad 1992), is important to the fitness of individuals. Working on ayu, Kishino (2004) reported that fish standard length (SL) at the time of upstream migration was unrelated to latitude. Fish at higher latitudes had slower growth rates but migrated upstream at older ages (reviewed by Kishino 2009). That study pooled literature data from both sides of the archipelago across multiple years.

In the present study, we aimed to determine the geographic variation in size of ayu at upstream migration, as well as growth patterns before upstream migration, by separately analyzing data on populations from the eastern (Pacific Ocean) and western (Sea of Japan) coasts of Japan. Our working hypothesis was that, contrary to the results of Kishino (2004), size at upstream migration would increase with increasing latitude, which was deduced from the latitudinal variations of body size commonly seen in ectotherms. To explain the observed patterns, we addressed 2 additional queries: (1) how marine growth rates and age at upstream migration are associated with the latitudinal clines of migration size, and (2) to what extent the seasonality in individual growth curves accounts for the latitudinal patterns observed in mean growth rates and migration size. 


\section{MATERIALS AND METHODS}

\subsection{Life cycle and population structure}

Ayu spawn in rivers and their eggs hatch into larvae during autumn to early winter. The larvae drift downstream to the sea where they metamorphose into juveniles approximately $60 \mathrm{~d}$ after hatching (at $\sim 27 \mathrm{~mm}$ SL; Fukuhara \& Fushimi 1986). Juveniles overwinter in nearshore areas (e.g. surf zones or estuaries) and, after about 4-6 mo, migrate back into rivers (Fig. 1). Sexual maturation and spawning is induced by shorter photoperiods and lower water temperatures (Hotta 1953, Shiraishi \& Takeda 1961, Kusuda 1963). Shiraishi \& Suzuki (1962) reported that the starting date of spawning was earlier at higher latitudes. The onset of upstream migration is also temperature-dependent, beginning once river and seawater temperatures increase to a particular range and after body length reaches approximately 60 mm (Hotta 1953, Kusuda 1963).

Population structure in terms of migration dynamics across rivers is far from completely understood for this species, particularly the quantitative aspects. A longstanding view is that this species lacks the ability of long-distance migration in the sea: that is, a certain proportion of individuals show natal homing whereas others migrate into the adjacent rivers (albeit no quantitative evidence exists). This view is supported by a few lines of evidence. First, spatial differences in high resolution neutral markers suggest a typical, isolation-by-distance pattern (Takeshima et al. 2016).
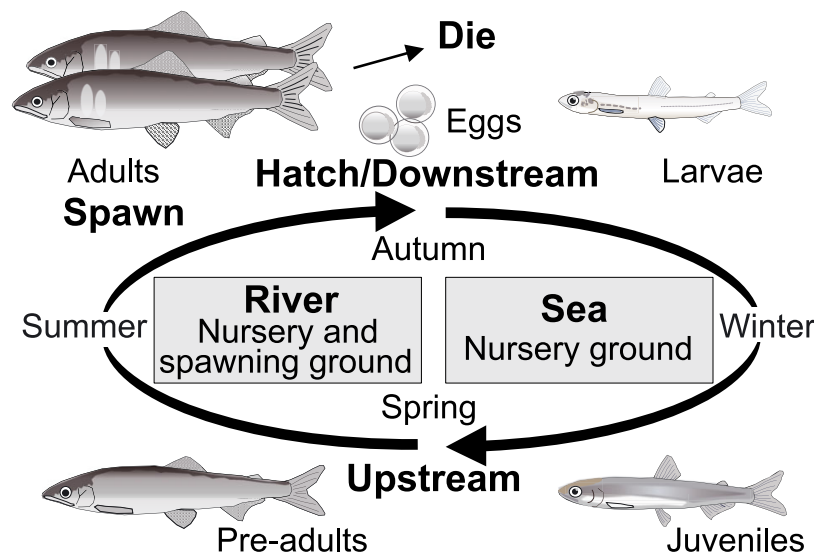

Fig. 1. Annual amphidromous life cycle of ayu Plecoglossus altivelis altivelis. Eggs are spawned in rivers from autumn to early winter; newly hatched larvae drift downstream toward the sea (top). Larvae grow mainly in the surf zone of coastal areas, and metamorphose into juveniles in winter (right); the upstream migration of juveniles into rivers occurs in spring (bottom). After growing in rivers during summer (left), ayu become sexually mature in autumn and die soon after spawning
Second, larval surveys suggest that larvae are passively dispersed between $2 \mathrm{~km}$ (Yamamoto et al. 2008) and $30 \mathrm{~km}$ (Senta 1967) from the mouth of their natal river. As ontogeny progresses, the fish obtain an ability to swim into coastal waters for overwintering and forthcoming river entry. In this context, we consider that the ayu is potentially suitable for examining latitudinal variation because, even in the marine stage, phenotypic patterns should reflect local environmental conditions in the vicinity of the natal river. For the same reason, we hereafter use the term 'population' in the sense of individuals living in the same river.

\subsection{Fish collection}

In total, 231 juvenile ayu were randomly collected, in 2001, from the lower courses of 23 Japanese rivers (Fig. 2, Table 1): 11 rivers along the Sea of Japan side (SJS), and 12 rivers on the Pacific Ocean side (POS). Collected specimens were immediately stored in $99 \%$ ethanol on-site.

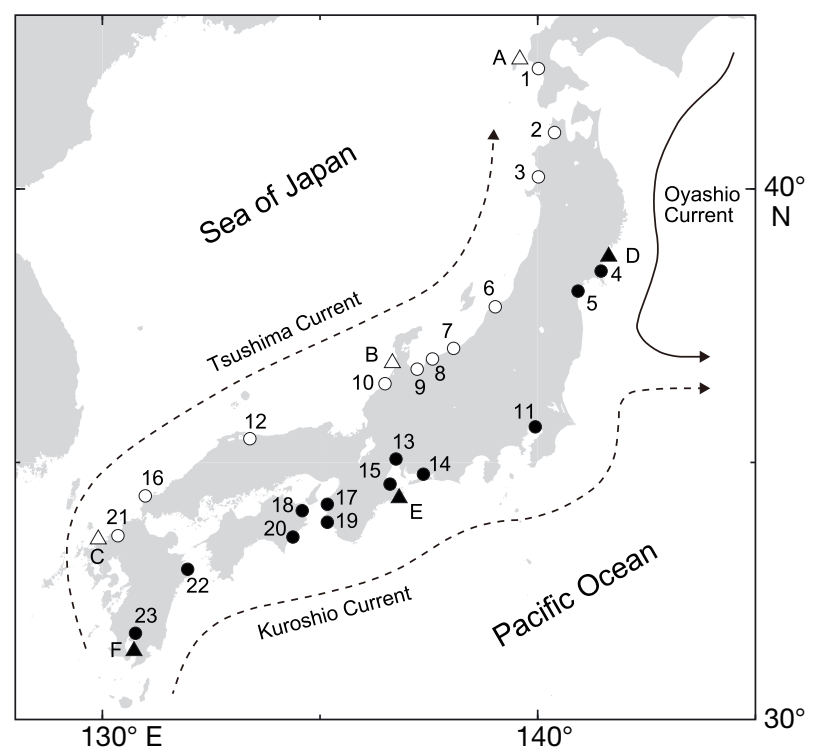

Fig. 2. Collection sites of 23 populations of ayu, from 11 rivers on the Sea of Japan side (open circles), and 12 rivers on the Pacific Ocean side (solid circles). 1: Kenichi River; 2: Iwaki River; 3: Tokiwa River; 4: Kitakami River; 5: Hirose River; 6: Shinano River; 7: Tokuai River; 8: Sasa River; 9: Jintsu River; 10: Tedori River; 11: Edo River; 12: Hino River; 13: Nagara River; 14: Toyo River; 15: Kushida River; 16: Awano River; 17: Kino River; 18: Yoshino River; 19: Hidaka River; 20: Kaifu River; 21: Muromi River; 22: Banjo River; and 23: Amori River. Triangles marked A-F represent locations where monthly mean sea surface temperatures were recorded (see Fig. S1 in the Supplement at www.int-res. com/articles/suppl/m624p143_supp.pdf). A: Hokkaido; B: Ishikawa Prefecture; C: Saga Prefecture; D: Miyagi Prefecture; E: Mie Prefecture; and F: Kagoshima Prefecture. Dashed arrows: warm currents; solid arrow: cold currents 
Table 1. Collection data for the ayu analyzed. Identification numbers of the rivers correspond to those shown in Fig. 2. ${ }^{a}$ River (population) samples for which otolith chemical analysis was conducted on all individuals collected. SJS: Sea of Japan side; POS Pacific Ocean side

\begin{tabular}{|c|c|c|c|c|c|}
\hline No. & River name & $\begin{array}{l}\text { Latitude } \\
\left({ }^{\circ} \mathrm{N}\right)\end{array}$ & $\begin{array}{l}\text { Longitude } \\
\left({ }^{\circ} \mathrm{E}\right)\end{array}$ & $\begin{array}{l}\text { Sampling } \\
\text { date }\end{array}$ & $\begin{array}{l}\text { Sample } \\
\text { size }\end{array}$ \\
\hline $1^{\mathrm{a}}$ & Kenichi (SJS) & 42.12 & 140.02 & 24 July & 11 \\
\hline 2 & Iwaki (SJS) & 41.01 & 140.37 & 25 May & 10 \\
\hline $3^{\mathrm{a}}$ & Tokiwa (SJS) & 40.22 & 140.01 & 29 May & 10 \\
\hline $4^{\mathrm{a}}$ & Kitakami (POS) & 38.57 & 141.44 & 25 April & 10 \\
\hline $5^{\mathrm{a}}$ & Hirose (POS) & 38.21 & 140.91 & 8 May & 10 \\
\hline 6 & Shinano (SJS) & 37.91 & 139.00 & 15 May & 10 \\
\hline $7^{\mathrm{a}}$ & Tokuai (SJS) & 37.14 & 138.06 & 6 June & 10 \\
\hline 8 & Sasa (SJS) & 36.96 & 137.57 & 14 May & 10 \\
\hline $9^{\mathrm{a}}$ & Jintsu (SJS) & 36.76 & 137.22 & 15 May & 10 \\
\hline $10^{\mathrm{a}}$ & Tedori (SJS) & 36.49 & 136.48 & 7 June & 10 \\
\hline $11^{\mathrm{a}}$ & Edo (POS) & 35.68 & 139.94 & 18 April & 10 \\
\hline $12^{\mathrm{a}}$ & Hino (SJS) & 35.46 & 133.37 & 6 May & 10 \\
\hline 13 & Nagara (POS) & 35.07 & 136.70 & 5 April & 10 \\
\hline $14^{\mathrm{a}}$ & Toyo (POS) & 34.78 & 137.35 & 18 May & 10 \\
\hline 15 & Kushida (POS) & 34.61 & 136.57 & 1 May & 10 \\
\hline 16 & Awano (SJS) & 34.36 & 130.97 & 6 April & 10 \\
\hline 17 & Kino (POS) & 34.22 & 135.14 & 29 March & 10 \\
\hline 18 & Yoshino (POS) & 34.09 & 134.57 & 8 May & 10 \\
\hline 19 & Hidaka (POS) & 33.88 & 135.15 & 22 March & 10 \\
\hline $20^{\mathrm{a}}$ & Kaifu (POS) & 33.59 & 134.36 & 11 May & 10 \\
\hline 21 & Muromi (SJS) & 33.59 & 130.34 & 13 March & 10 \\
\hline 22 & Banjo (POS) & 32.97 & 131.93 & 29 March & 10 \\
\hline 23 & Amori (POS) & 31.72 & 130.74 & 25 April & 10 \\
\hline
\end{tabular}

We aimed to collect fish at the onset of their migration into rivers because (1) body sizes of individuals at upstream migration decrease with time within the same upstream migration season (Tago 2004), and (2) the leading group was certain to comprise wild-born individuals and not hatchery-reared fish released after this event. In theory, the onset of upstream migration is defined as the point in time when the first migratory individual enters the lower course of a river. Therefore, 'SL at catch' and 'age at catch' should exactly reflect those data at time of upstream migration, given that the individuals were successfully collected the start of their upstream migration. Although our sampling was designed to capture the first individuals migrating back to rivers, it is possible that some early migrants may have been missed. Thus, we performed otolith chemical analysis to ensure that each individual fish had been collected immediately after its river entry.

\subsection{Otolith increment analysis}

A sagittal otolith was extracted from each individual, and daily rings were counted in order to estimate
SL at upstream migration and to describe individual growth trajectories. Each otolith was embedded in epoxy resin (EpoFix or SpeciFix, Struers or Petropoxy; Maruto Instrument) and mounted on a glass slide. The embedded otolith specimens were ground with SiC Foil (grit \#180, \#1200, \#2000, \#4000; Struers) on a polishing wheel (RotoPol-35; Struers) to expose a sagittal section through the core. The ground surfaces were then buffed with an active oxide polishing suspension (OP-S suspension; Struers) on a polishing wheel fitted with a semi-automatic specimen mover (MD-Chem and RotoPol-35/PdM-Force-20; Struers). Daily rings were counted using a system consisting of a light microscope with 50-1000× magnification, a couple-charged device (CCD) camera, and a computer-controlled image analyzer (Jiseki 8; Ratoc System Engineering Company). Otolith radius and its incremental widths were measured along a line from the core to the posterior edge (Figs. 3a \& S2).

\subsection{Otolith chemical analysis}

To estimate the date of upstream migration for each individual, the ratio of the concentration of strontium $(\mathrm{Sr})$ to calcium $(\mathrm{Ca})$ in otoliths was measured. This ratio reflects the salinity of ambient water at the time of otolith precipitation (Otake \& Uchida 1998). Samples were cleaned in an ultrasonic bath, rinsed for 1 min with $99 \%$ ethanol, rinsed for $1 \mathrm{~min}$ with deionized water (for dedusting), and then dried and coated with platinum-palladium (Pt-Pd) in an ion-beam sputter (E-1030; Hitachi) to enhance the electrical conductivity (Gunn et al. 1992). By using a wavelength-dispersive $\mathrm{X}$-ray electron microprobe analyzer (JXA-8230; JEOL), both the Ca and Sr concentrations were measured at $5 \mu \mathrm{m}$ intervals across the longest axis of the otolith, from the core to the edge. The accelerating voltage and beam current were $15 \mathrm{kV}$ and $1.2 \times 10^{-8} \mathrm{~A}$, respectively. The electron beam was focused on a point measuring $5 \mu \mathrm{m}$ in diameter. Strontium titanate $\left(\mathrm{SrTiO}_{3}\right)$ and wollastonite $\left(\mathrm{CaSiO}_{3}\right)$ were used as standards.

The raw Sr:Ca ratio at each specific daily age was calculated and a $5 \mathrm{~d}$ moving average was used to reduce the effect of measurement error (Fig. 3b). The $\mathrm{Sr}$ :Ca decreases to $\leq 2.4$ once ayu migrate back into rivers (Hata et al. 2016). Therefore, we defined the date of upstream migration as the date when the movingaveraged Sr:Ca first scored less than 2.4 (Fig. 3b).

Otolith chemical analysis was performed in a 2tiered approach. In the first step, 2 individuals were randomly chosen from all individuals collected from 

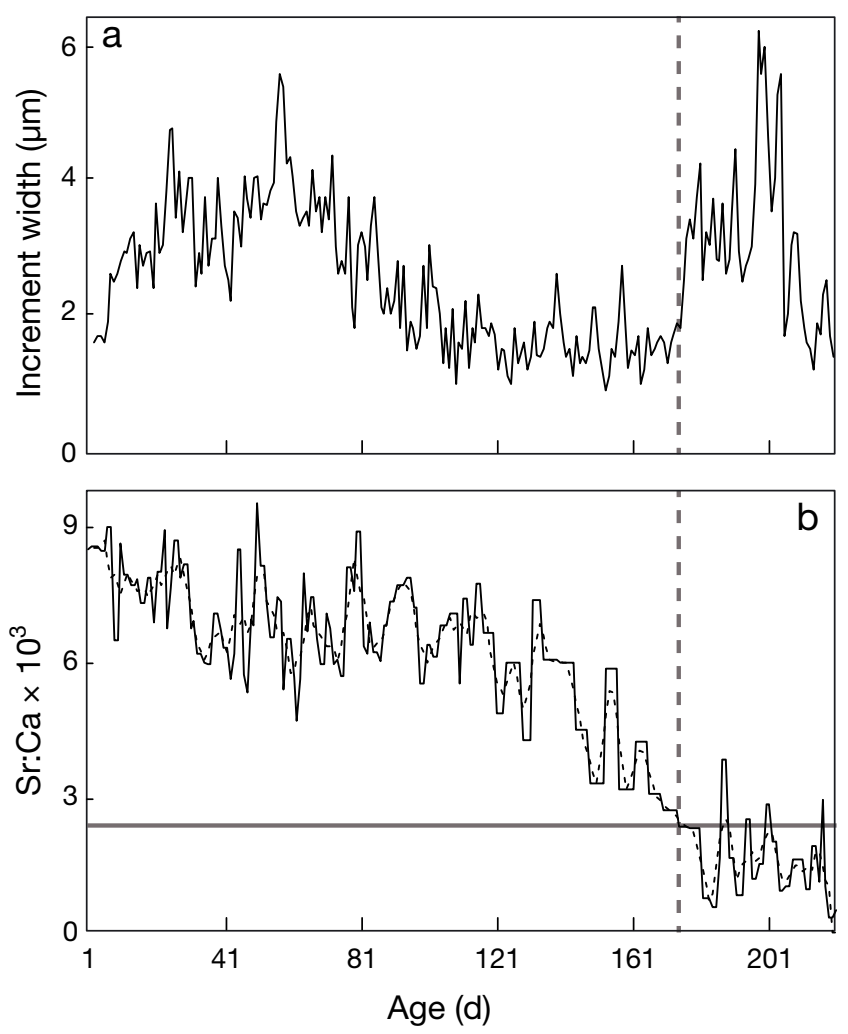

Fig. 3. Example of data obtained from the otolith increment and chemical analyses of ayu \#07 from the Hirose River on the Pacific Ocean side of Japan. (a) Otolith radius increments, and (b) strontium/calcium (Sr:Ca) ratios, plotted against fish age, with a dashed line drawn by connecting $5 \mathrm{~d}$ moving averages of raw values of the $\mathrm{Sr}$ :Ca after replacing missing or abnormal $\mathrm{Sr}$ :Ca values with the arithmetic mean of the previous and next values (if any). The Sr:Ca ratio in otoliths decreases as the ayu move upriver from a river mouth. We assumed upstream migration occurred when the $5 \mathrm{~d}$ moving average of $\mathrm{Sr}$ :Ca fell below 2.4 (horizontal grey line). Vertical dashed lines: fish age at time of upstream migration

the same river and their Sr:Ca was measured (it was not feasible to analyze the entire river sample). If both individuals had ratios that were greater than 2.4 throughout the time-series, the collecting date was used as a proxy of the ascending date (upstream migration) for all the individuals collected from the river. Otherwise, as the second step, we used the entire sample from the river for otolith chemical analysis. Based on this criterion, otolith chemical analyses were performed on all fish for populations from 11 of the 23 rivers (see Table 1). Note that chemical analyses were performed on all individuals captured in the Kenichi River (i.e. the northernmost sampling site). In this river, all individuals had been collected several months after upstream migration. The possible impact of this exception to the sampling design on the results is discussed in Section 4.

\subsection{Body-size estimation}

In the laboratory, fish were measured for SL to the nearest $0.01 \mathrm{~mm}$, using digital calipers, prior to extracting the sagittal otoliths. For the individuals subjected to otolith chemical analysis, SL at upstream migration $\left(\mathrm{SL}_{\mathrm{usm}}\right)$ was estimated on the basis of otolith radius (OR), according to the biological intercept method (Campana 1990):

$\mathrm{SL}_{\text {usm }}=\mathrm{SL}_{\text {catch }}+\left(\mathrm{SL}_{\text {catch }}-\mathrm{SL}_{\text {hatch }}\right) \times \frac{\mathrm{OR}_{\text {usm }}-\mathrm{OR}_{\text {catch }}}{\mathrm{OR}_{\text {catch }}-\mathrm{OR}_{\text {hatch }}}$

where the subscripts 'hatch,' 'usm,' and 'catch' indicate corresponding sizes of the fish at the time of hatching out, upstream migration, and collection, respectively. As otolith radius at hatching $\left(\mathrm{OR}_{\text {hatch }}\right)$ cannot be exactly measured in this species, it was substituted with the distance from the otolith core to the innermost clear circle in the otolith increment observation (consequently $\mathrm{OR}_{\text {hatch }}$ was assumed to be approximately $15 \mu \mathrm{m}$ for all individuals). Otherwise, $\mathrm{SL}_{\mathrm{usm}}=\mathrm{SL}_{\mathrm{catch}}$ in the individuals considered to be collected at the time of upstream migration (i.e. those exempted from the otolith chemical analysis).

Both $\mathrm{SL}_{\text {hatch }}$ and $\mathrm{SL}_{\text {usm }}$ must be known to calculate the mean somatic growth rate at the marine stage. However, a hatching check is not visible in this species (Tsukamoto \& Kajihara 1987) and it is impossible to estimate individual hatching size from juvenile specimens. We therefore assumed that the hatching SL of all individuals was uniformly $6.1 \mathrm{~mm}$, following the method of Takahashi (2004). With this assumption, the mean somatic growth rate at the marine stage was calculated as $\mathrm{SL}_{\mathrm{usm}}(\mathrm{mm})$ minus $6.1 \mathrm{~mm}$, divided by the number of days until upstream migration.

\subsection{Statistical analysis}

The study centered on the geographical pattern of both SL and age at the start of upstream migration (which are referred to below as ascending SL and ascending age, respectively), as well as the mean somatic growth rate during the marine growing period. Individuals of both sexes were pooled in the following analyses because phenotypic sex cannot be morphologically determined at this life stage in ayu, 
and no previous study has reported evidence of sexual dimorphism in these traits. Ascending SL, marine growth rate, and ascending age were independently analyzed by applying an ANCOVA model, in which location (POS or SJS, the fixed-effect factor), latitude (covariate), and their interaction term (location $\times$ latitude) were treated as independent variables. To avoid possible pseudoreplication, arithmetic means of the individual data from a river were used as the dependent variables, because we cannot rule out the possibility that trait values for 10 of 11 individuals from the same river are autocorrelated with each other. Notably, the latitudinal position of each location (river) represents the latitude of the mouth of the corresponding river. These analyses also provide the least-square estimates (and their respective standard errors) of regression slopes between the covariate and dependent variable. As some dependent variables described a humped or asymptotic curve, the validity of fitting linear regression models was doubted. Consequently, we assumed a quadratic function between latitude and the phenotypic variables:

$$
y=a x^{2}+b x+c
$$

where $y$ is the dependent variable (e.g. ascending SL) and $x$ is the sampling latitude. The least-squares estimates of polynomial coefficients $a, b$, and $c$ were calculated by assuming the residual term to be a normal random variable, independent and identically distributed. The residual sum of squares ( $\mathrm{RSS}_{\mathrm{QUAD}}$ ) was calculated to check whether the implementation of a quadratic term improved model fit, which was used for calculating the statistic $F$ as follows:

$$
F \equiv \frac{\left(\mathrm{RSS}_{\mathrm{ANCOVA}}-\mathrm{RSS}_{\mathrm{QUAD}}\right) /\left(\theta_{\mathrm{QUAD}}-\theta_{\mathrm{ANCOVA}}\right)}{\mathrm{RSS}_{\mathrm{QUAD}} /\left(N-\theta_{\mathrm{QUAD}}\right)}
$$

where $\theta$ is the number of parameters to be estimated, and $N$ is the total number of populations (i.e. $\mathrm{n}=23$ rivers). The subscript ANCOVA indicates the ANCOVA model explained above, in which 2 main effects and their interaction term were always assumed (i.e. $\theta_{\text {ANCOVA }}=4$ ). The ANCOVA model was compared with an alternative model designated QUAD (i.e. $\left.\theta_{\text {QUAD }}=6\right)$, in which the relationship between latitude and the phenotypic variable is given by Eq. (2). The statistic (Eq. 3) follows an F-distribution, with $\theta_{\mathrm{QUAD}^{-}}$ $\theta_{\text {ANCOVA }}$ and $N-\theta_{\text {QUAD }}$ degrees of freedom under the null hypothesis that the quadratic term leads to no improvement in model fit (see Faraway 2002, Ruppert et al. 2003, Irie et al. 2013).

Daily otolith-increment data were sufficiently informative to estimate the growth trajectory of each individual in the marine stage (Fig. S3). In particular, when plotting the otolith radius against age, we noticed that some individuals showed an S-shaped growth trajectory and others an inverse S-shaped curve. This variation can be quantitatively evaluated by describing an individual growth curve by a cubic polynomial function and then focusing on its cubicterm coefficient. We thus assumed the following function:

$$
y=k_{3} x^{3}+k_{2} x^{2}+k_{1} x
$$

where $y$ is the relative radius from the nucleus of the otolith, and $x$ is the relative age of the individual fish, and the parameters $k_{1}, k_{2}$, and $k_{3}$ were estimated by least-squares fitting. For this procedure, to compare the shape of growth curves among individuals, raw observations were standardized in such a manner that otolith radius at upstream migration increases from 0 to 1 , and the length of the marine stage is 1 . We focused on the value of the coefficient of the cubic term $\left(k_{3}\right)$, because negative scores $\left(k_{3}<0\right)$ are associated with $\mathrm{S}$-shaped growth trajectories and vice versa. In order to recognize geographic patterns in growth-curve shapes, the cubic-term coefficient $\left(k_{3}\right)$ was statistically analyzed by applying an ANCOVA model with location, latitude, and location $\times$ latitude as independent variables. All analyses were performed using JMP Pro v.13.0.0 statistical software for Windows (SAS Institute).

\section{RESULTS}

\subsection{Latitudinal clines in life-history traits}

Clear latitudinal clines were found in ascending SL (Table S1). These clines showed a clear opposite pattern between the 2 water bodies. For example, at the start of migration, ayu were larger at higher latitudes on the POS, but smaller in the SJS (Fig. 4, Table S1). This finding was compatible with the ANCOVA results on ascending $\mathrm{SL}$, in which the interaction between location and latitude was statistically significant ( $p<0.05$; Table $\mathrm{S} 2$ ). Age at upstream migration increased significantly with latitude $(\mathrm{p}<0.001$; Fig. 5a), whereas neither the location $\times$ latitude interaction nor the location effects were significant (both p > 0.05; Table S3). Conversely, marine growth rates described a monotonically decreasing trend with increasing latitude (Fig. 5b), which was statistically supported by a significant latitude main effect in the ANCOVA ( $p=0.043$; Table S4). Neither the location $\times$ latitude interaction nor the location effects were 


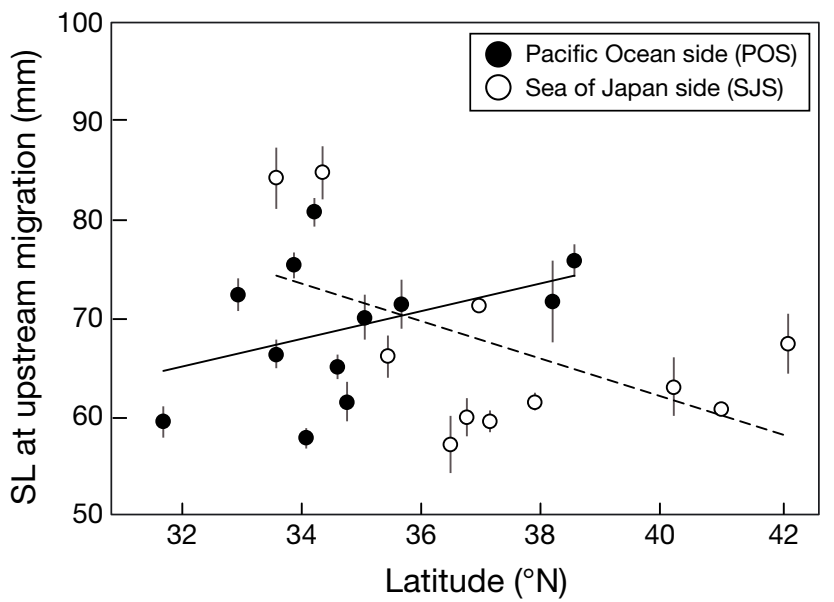

Fig. 4. Relationship between latitude (Lat) and mean standard length (SL) of ayu at time of upstream migration. Circles: the mean SL of populations on either the Pacific Ocean side (POS, $\mathrm{n}=120$ fish) or Sea of Japan side (SJS, $\mathrm{n}=111$ fish). Vertical bars: SE of the mean SL. Solid and dashed lines: ANCOVA result for the POS and SJS populations, respectively (Table S2 in the Supplement). Least-square point estimates $( \pm \mathrm{SE})$ were $a=1.440( \pm 1.070)$ and $b=19.156$ $( \pm 37.280)$ for POS, and $a=-1.966( \pm 1.030)$ and $b=140.741$ $( \pm 38.682)$ for SJS, where SL $=a$ Lat $+b$

significant (both $\mathrm{p}>0.05$; Table S4). Nevertheless, for the age at upstream migration, fitting parabolic curves was preferred by means of the F-tests on the basis of the difference of RSS between the ANCOVA and quadratic polynomial models (Table S5a-C, Figs. S4-S6). This occurred mainly because individuals in the northernmost SJS population deviated from the linear latitudinal cline, having shorter marine periods than expected (Fig. S5).

\subsection{Growth trajectories estimated by the otolith microscopic analysis}

Looking at ontogenetic trajectories of otolith radius, the shapes showed a weak shift from S-shaped to inverse S-shaped curves with increasing latitude (Figs. 6, S7 \& S8). Table S6 summarizes the ANCOVA results on the cubic-term coefficient, indicating that latitudinal clines were statistically significant $(p=$ 0.007), with a non-significant interaction between latitude and location $(p>0.05)$, although the slopes were considerably different between the 2 water bodies. A quadratic function was fitted (instead of the ANCOVA model) to the obtained latitudinal plots of the cubic-term coefficient $\left(k_{3}\right)$, but, as reported in Table S5d and Fig. S7, the resulting decrease in the RSS was non-significant. Among-population variation in $k_{3}$ was plotted against mean marine growth

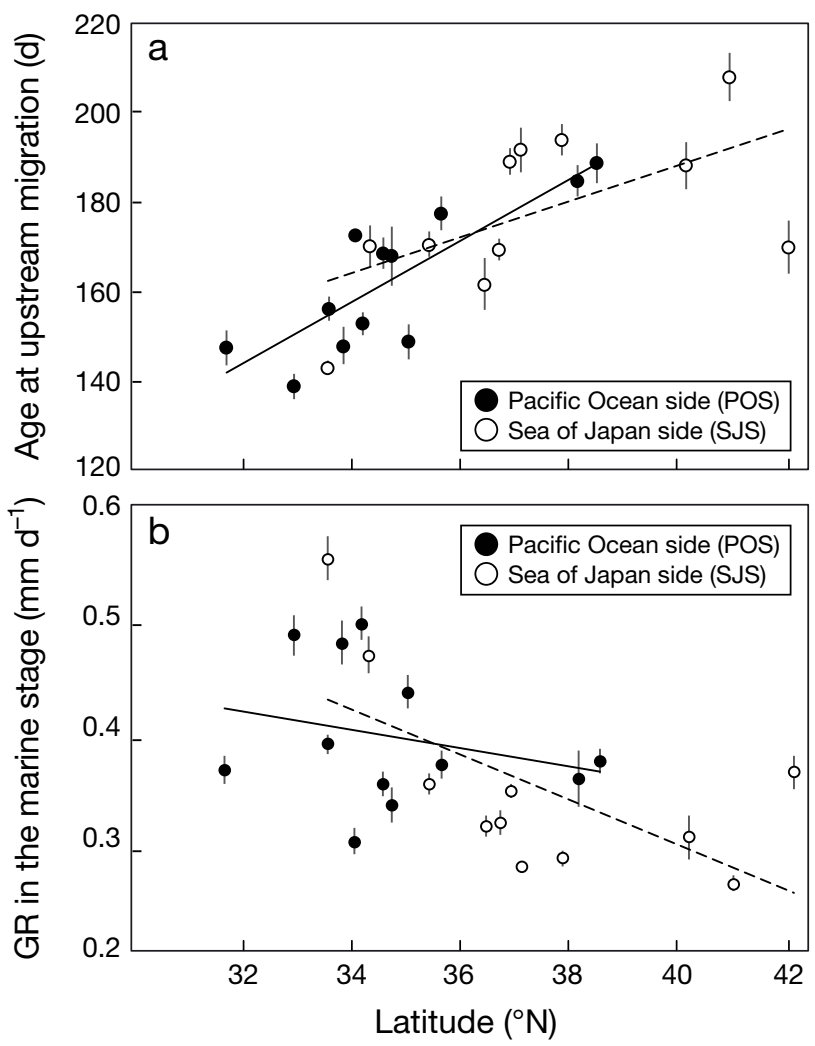

Fig. 5. (a) Relationship between latitude (Lat) and mean age at upstream migration (Age). Least-square point estimates $( \pm \mathrm{SE})$ of the ANCOVA model $($ Age $=a$ Lat $+b)$ are $a=7.070$ $( \pm 1.502)$ and $b=-82.240( \pm 52.315)$ for populations on the Pacific Ocean side (POS, solid line), and $a=4.140( \pm 1.876)$ and $b=24.213( \pm 70.433)$ for populations on the Sea of Japan side (SJS, dashed line) (see also Table S3). (b) Relationship Lat and mean growth rates (GR). Least-square point estimates $( \pm \mathrm{SE})$ of the model $(\mathrm{GR}=a$ Lat $+b)$ are $a=-0.008$ $( \pm 0.010)$ and $b=0.672( \pm 0.342)$ for POS (solid line), and $a=$ $-0.020( \pm 0.008)$ and $b=1.103( \pm 0.315)$ for SJS (dashed line) (see also Table S4). Circles represent the mean values for populations from POS ( $\mathrm{n}=120$ fish) or SJS ( $=111$ fish). Vertical bars: SE of the mean

rates (Fig. 7). Negative correlations were found among populations on both the SJS $(\mathrm{r}=-0.876, t=$ -5.437, $\mathrm{p}<0.001)$ and POS $(\mathrm{r}=-0.654, t=-2.737, \mathrm{p}=$ 0.021 ; Fig. 7), indicating that the wintertime check on somatic growth largely accounts for the geographic variability of mean growth rates.

\section{DISCUSSION}

\subsection{Latitudinal clines and temperature gradients}

An obvious finding of the present study is that, contrary to our original working hypothesis, latitudinal 


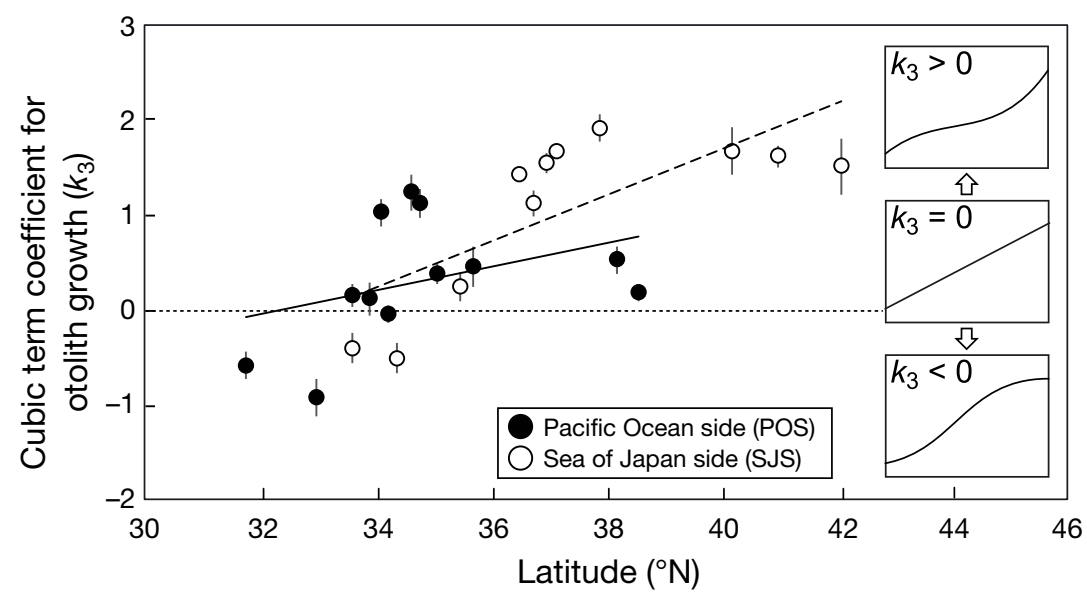

Fig. 6. Relationship between latitude (Lat) and shape of the otolith growth curves $\left(k_{3}\right)$. Vertical axis: least-square estimate of the third-order term coefficient calculated by fitting a cubic polynomial function to the time-series of otolith-radius data. Circles: estimates for populations from the Pacific Ocean side (POS, $\mathrm{n}=120$ fish) or Sea of Japan side (SJS, n = 111 fish), with standard errors of the mean $k_{3}$ (vertical bars). A negative coefficient $\left(k_{3}<0\right)$ leads to an S-shaped growth curve, while a positive coefficient $\left(k_{3}>0\right)$ leads to an inverse S-shaped growth curve. Least-square point estimates $( \pm \mathrm{SE})$ of the model are $a=0.113( \pm 0.088)$ and $b=-3.824( \pm 3.061)$ for POS (solid line), and $a=0.219$ $( \pm 0.066)$ and $b=-7.409( \pm 2.470)$ for SJS (dashed line), where $k_{3}=a$ Lat $+b$ (see also Table S6)

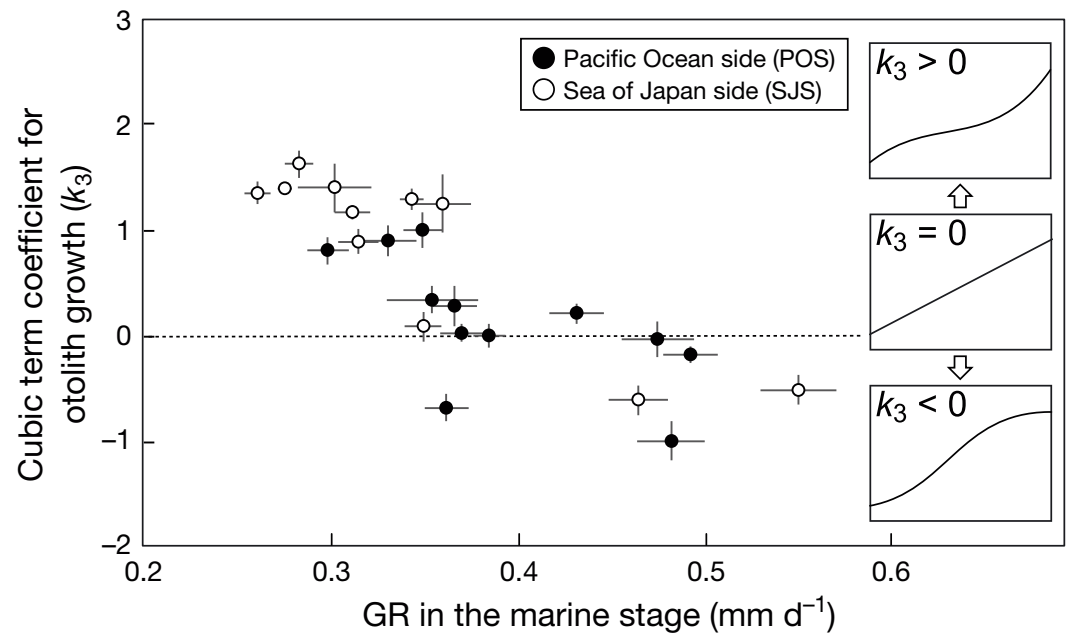

Fig. 7. Mean marine growth rates (GR) and shape parameter for the otolith growth curves $\left(k_{3}\right)$ for ayu collected from the Pacific Ocean side $(\mathrm{n}=120)$ or the Sea of Japan side $(n=111)$. Horizontal and vertical bars: SE of the means for the corresponding axis

clines of upstream size of ayu were reversed between the 2 sides of the Japanese Archipelago. To the best of our knowledge, no previous studies have documented a case in which both positive and negative latitudinal clines were found in different areas for the same trait within a species. This finding also disagrees with previous reports showing that size at the beginning of upstream migration does not depend on the latitude for this species (Kishino 2004, 2009). Our assumption is that previous studies did not detect the latitudinal clines probably due to the pooling of data from the 2 water bodies. In fact, statistical significance for latitude disappeared when we performed the ANCOVA after removing the location main effect from our model. In the following paragraphs, we develop this argument after assuming that the observed patterns can be simply explained by the spatiotemporal dynamics of environmental conditions (e.g. ambient temperatures and food availability), tentatively ruling out the possibility that genetic components in phenotypic variances might also be responsible (cf. Takeshima et al. 2016 for population subdivisions).

A counter-directional pattern between the 2 water bodies was not seen in the mean growth rates or in the age at upstream migration. The latitudinal clines of marine growth rates were negative on both sides of the Japanese Archipelago. This pattern is commonly seen in aquatic ectotherms exposed to thermal gradients, as higher temperatures always lead to faster growth (Atkinson 1994) as long as thermal inhibition does not occur (Angilletta 2009). In contrast, age at upstream migration positively depended on latitude on both sides of the archipelago, which was consistent with previous reports by Kishino (2004, 2009). This pattern is typical among ectotherms in the sense that the length of a given life-history stage (i.e. development time), generally increases in duration with decreasing environmental temperatures in the absence of the time constraint due to season length. This can be rephrased as a positive relationship between environmental temperature and development rate, defined as the reciprocal of the development time for the ontogenetic stage (see Forster \& Hirst 2012). Using this terminology, the patterns observed in this study demonstrate development rates that are more temperature-dependent than the growth rates for the POS populations, 
resulting in a positive latitudinal cline of size at upstream migration - and vice versa for the SJS populations.

A phenological response to the seasonality of environmental parameters (e.g. temperature or day length; Uchida et al. 1990) may also be responsible for the geographic variations in age at upstream migration. From a behavioral point of view, seasonal changes in both seawater and river-water temperatures should be considered since upstream migration in this species is cued by river-water temperatures that gradually warm up in spring and eventually reach seawater temperatures (Hotta 1953, Kusuda 1963). This explanation is compatible with the positive latitudinal clines of age at upstream migration, because a rise in riverine temperatures in the spring occurs later at higher latitudes, which also accounts for the fact that spawning occurs earlier at higher latitudes in this species (Shiraishi \& Suzuki 1962).

\subsection{Underlying mechanisms of the counter- directional size clines}

The counter-directional latitudinal clines observed in size at upstream migration should be understood in a manner consistent with the latitudinal patterns of the other 2 traits, because size at upstream migration integrates both mean growth rate and age at upstream migration (the influence of variation in size at hatch is assumed to be negligible). Age at upstream migration increased more rapidly with latitude for populations on the POS than on the SJS. Opposite latitudinal trends in mean growth rate were also observed, although the slope was less steep for the POS populations. Although these differences in regression slopes were not statistically significant, they can be considered biologically significant. In short, we propose that a pronounced positive latitudinal gradient in body size arises from the combination of a weaker latitudinal dependence of mean growth rate and a relatively stronger latitudinal dependence of age at upstream migration for the POS populations.

For age at upstream migration, populations at latitudes higher than $42^{\circ} \mathrm{N}$ were obviously responsible for less steepness in the regression lines for the SJS populations. In these populations, the growing period in the sea was shorter than expected from the straight regression line between latitude and age at upstream migration. The pattern observed in one highlatitude population (Kenichi River, Fig. 2) requires some explanation other than the behavioral response to temperature difference between the ocean and rivers, as mentioned above. We suspect that this outlier occurred simply because sampling was performed several months after the expected upstream migration season in this river, which is exceptionally different from the other localities (see Section 2.2). Our results support the possibility that individuals with relatively young age at the time of upstream migration were selected out several months before sampling, but the selective agent cannot be specified from our data.

The latitudinal cline of mean growth rates was steeper in the SJS. Notably, this can be primarily attributed to relatively fast growth in 2 populations in the Genkai Sea (nos. 16 and 21, Fig. 2). These 2 populations are distinct from the other SJS populations in the sense that otolith growth described S-shaped curves. The shape of the otolith growth curves is highly likely to reflect seasonal changes in temperature experienced by each individual. For example, inversed S-shaped growth curves should represent decelerated growth probably caused by low seawater temperatures in winter, as seen in the negative correlations between the mean growth rates and the shape parameters of the otolith growth curve (Fig. 7). Conversely, the 2 populations in the Genkai Sea would be free from slowed growth owing to low temperatures in winter, which resulted in higher mean growth rates. We speculate that fish might overwinter by remaining in locally warm microhabitats, as the observed faster growth in these populations obviously deviated from the macrogeographic pattern of seawater surface temperatures in the Sea of Japan (Fig. S1). Our conjecture is supported by the work of Otake (2006), who proposed, as the most likely hypothesis, that ayu stay on the bottom of a coastal sea until approximately $30 \mathrm{~d}$ after hatching ( 5-20 $\mathrm{mm}$ in body length), and then spend the next $60 \mathrm{~d}$ in benthic habitats in the surf zone ( 20-30 $\mathrm{mm}$ in body length) for overwintering.

\subsection{Possible determinants of growth rate other than temperature}

The impact of food availability on growth rates could not be ruled out, but it might be limited as a determinant of the clines observed in our data. Ayu mainly feed on copepods in the sea (Hamada \& Kinoshita 1988), and abundances of these generally increase with increasing latitude, particularly in the Pacific (Yamaguchi et al. 2017). A latitudinal gradient in food availability cannot be the dominant cause of growth-rate clines because these trends are latitudi- 
nally in the opposite direction (fish growth is slower at higher latitudes where prey density is higher). At the same time, we assume that food limitations potentially impact only at lower latitudes, considering the thermal dependency of the imbalance between metabolism and food availability. In ectotherms, energetic demands for basic metabolism increase with increasing temperature, which also allows faster somatic growth when no constraints on energy uptake exist (i.e. ad libitum food consumption). Alternatively, higher temperatures are expected to depress growth rates more significantly if food availability is less than a certain threshold, as net energy flux to growth decreases (Kooijman 2000). From this viewpoint, the observed latitudinal patterns in otolith growth curves seem to be mostly explained by latitudinal patterns of temperature seasonality, rather than those of prey availability.

A larger size at hatching should lead to a larger size at upstream migration given all other conditions are more-or-less equal. In the present study, however, we tentatively assumed that hatching size bears no significant variation among ayu populations because fish size estimated by microscopic observation of the otoliths is not accurate for this species. For the same technical reason, no previous study has examined the possible geographic variation of this trait in this species. The most relevant fact for our attention is that ayu egg size decreases with increasing latitude on both sides of the Japanese Archipelago (Iguchi 1993), contrary to the plastic response of egg size to temperature commonly seen in ectotherms (e.g. Kokita 2003). The negative latitudinal cline of egg size in ayu is probably attributable to phenotypic plasticity, which dictates that smaller females produce larger-sized eggs (and larger hatchlings). This reaction norm was experimentally demonstrated by Iguchi (2012), whereby ayu egg diameter, larval notochord length at hatching, and yolk mass were compared among maternal individuals with different body sizes, prepared by controlling the food supply in laboratory experiments. At least on the Pacific side, the negative latitudinal cline of egg size in ayu is most likely to be a direct outcome of the adult-size variation complying with the temperature-size rule, considering that there is a positive correlation between ascending size and maturation size in this species (Murase et al. 2018). Conversely, the negative latitudinal cline of egg size cannot be a cause of the positive latitudinal cline of size at upstream migration within the same generation; the egg-size variation should produce a less-steep body-size cline due to the temperature-size rule.

\subsection{Ecological factors responsible for outliers}

Some of the variation in our measurements (deviations from regression lines) can be plausibly explained by differences in local environmental conditions. For example, the shape parameter $\left(k_{3}\right)$ of the otoliths from fish in the 2 northernmost populations on the Pacific side (nos. 4 and 5, Fig. 2) were not as high as would be expected from the regression with latitude (e.g. Fig. 6). The observed S-shaped curves suggest that these Miyagi Prefecture populations were able to avoid the low water temperatures characteristic of the winter period at these higher latitudes. Consequently, the latitudinal regression line of mean growth rates was less steep for the Pacific Ocean populations. The fast growth of fish in these populations was unexpected based on the prevailing sea surface temperatures (Fig. S1) and it is most likely that fish overwintered in microhabitats offering a thermal refuge against low temperatures, as discussed above for the Genkai Sea populations. It would be possible to test for the presence of thermal refugia by measuring stable oxygen isotopes in otoliths.

In the northernmost population in the Sea of Japan (no. 1, Fig. 2), exceptionally fast growth and a short growing period were observed (Fig. 5). The explanation based on a thermal refuge (see above) cannot be applied to this population, because otolith growth describes an inverse S-shaped curve (Fig. 6; i.e. retarded growth during overwintering). Alternatively, this may be an artefact of collecting these fish several months after the onset of upstream migration in this river; i.e. our sample was a mixture of early and later migrants. One may wonder why the withinpopulation phenotypic variances of this river are comparable with the other rivers (see error bars in Figs. 4, 5, \& 6), nevertheless. This inconsistency seems to be resolved if the population was subject to stabilizing selection in favor of rapid riverine growth and/or catch-up growth in late-born individuals.

\section{CONCLUSIONS}

We found that latitudinal clines in body size at upstream migration and its related traits in the early ontogenetic stage of ayu were different in populations on the 2 sides of the Japanese Archipelago. This finding emphasizes that the direction of latitudinal clines of a trait can reverse between neighboring areas, even within a single species. This should be taken into consideration in future ecological studies 
relevant to biogeographic patterns. Phenotypic clines on the eastern (Pacific Ocean) side agreed with patterns widely reported across ectotherms, wherein colder temperatures often induce larger sizes (i.e. the temperature-size rule), consistently accompanied by longer growing periods with slower growth rates (Sibly \& Atkinson 1994, Irie et al. 2013, Horne et al. 2015). In contrast, populations on the western (Sea of Japan) side had an opposite latitudinal cline in size at upstream migration, which partly resulted from mean growth rates exhibiting a steeper negative latitudinal cline than on the Pacific side. The anomalous trend is likely to reflect both seasonal and small/local scale properties of thermal environments experienced during overwintering, as suggested by the among-population comparison of the individual growth curves. Future studies should explore whether the patterns reported here are transient or persistent since considerable inter-annual variability in body size at the riverine stage has been reported in this species (Iguchi et al. 2011).

Acknowledgements. We thank Dr. Myron A. Peck and 3 anonymous reviewers for their careful reading of the manuscript and their many insightful suggestions. Fish specimens were provided by scientists at the Prefectural Fisheries Experimental Stations in Japan. We are grateful to Tsuguo Otake, Kotaro Shirai, Nobuhiro Ogawa, and Rey Amano for assistance with the otolith chemical analysis. We thank Yoshiro Watanabe, Tomohiko Kawamura, and Yoko Iwata for allowing use of instruments needed for the otolith increment analysis. This study was partly supported by a grant from the Japan Ministry of Agriculture, Forestry and Fisheries; a Grant-in-Aid for Scientific Research from the Japan Society for the Promotion of Science (no. 15K07538); and the cooperative program (no. 126, 2018) of the Atmosphere and Ocean Research Institute, The University of Tokyo.

\section{LITERATURE CITED}

Angilletta MJ (2009) Thermal adaptation: a theoretical and empirical synthesis. Oxford University Press, Oxford

Atkinson D (1994) Temperature and organism size: a biological law for ectotherms? Adv Ecol Res 25:1-58

* Belk MC, Houston DD (2002) Bergmann's rule in ectotherms: a test using freshwater fishes. Am Nat 160: 803-808

Billerbeck JM, Ortí G, Conover DO (1997) Latitudinal variation in vertebrate number has a genetic basis in the Atlantic silverside, Menidia menidia. Can J Fish Aquat Sci 54:1796-1801

Campana SE (1990) How reliable are growth back-calculations based on otoliths? Can J Fish Aquat Sci 47: 2219-2227

Conover DO, Present TMC (1990) Countergradient variation in growth rate: compensation for length of the growing season among Atlantic silversides from different latitudes. Oecologia 83:316-324
Faraway JJ (2002) Practical regression and ANOVA using R. Bath University Press, Bath

*Forster J, Hirst AG (2012) The temperature-size rule emerges from ontogenetic differences between growth and development rates. Funct Ecol 26:483-492

Fukuhara O, Fushimi T (1986) Development and early life history of the ayu reared in the laboratory. Bull Jpn Soc Sci Fish 52:75-80 (in Japanese with English Abstract)

* Gunn JS, Harrowfield IR, Proctor CH, Thresher RE (1992) Electron probe microanalysis of fish otolith - evaluation of techniques for studying age and stock discrimination. J Exp Mar Biol Ecol 158:1-36

Hamada R, Kinoshita I (1988) Feeding habit of larval and juvenile ayu, Plecoglossus altivelis in the surf zone of Tosa Bay, Japan. Jpn J Ichthyol 35:382-388 (in Japanese with English Abstract)

* Hata M, Kawakami T, Otake T (2016) Immediate impact of the tsunami associated with the 2011 Great East Japan Earthquake on the Plecoglossus altivelis altivelis population from the Sanriku coast of northern Japan. Environ Biol Fishes 99:527-538

*Horne CR, Hirst AG, Atkinson D (2015) Temperature-size responses match latitudinal-size clines in arthropods, revealing critical differences between aquatic and terrestrial species. Ecol Lett 18:327-335

Hotta H (1953) A note on the sea life of the young 'ayu'. Jpn J Ichthyol 3:15-20 (in Japanese with English Abstract)

Iguchi K (1993) Latitudinal variation in ayu egg size. Bull Jpn Soc Sci Fish 59:2087

* Iguchi K (2012) Egg-size plasticity corresponding to maternal food conditions in an annual fish, ayu Plecoglossus altivelis. Ichthyol Res 59:14-19

Iguchi K, Aino S, Awata S, Yodo T, Tago Y (2011) Recent limited growth of ayu Plecoglossus altivelis observed in Sho River. Aquat Sci 59:459-464 (in Japanese with English Abstract)

次 Irie T, Morimoto N, Fischer K (2013) Higher calcification costs at lower temperatures do not break the temperature-size rule in an intertidal gastropod with determinate growth. Mar Biol 160:2619-2629

Jensen AJ, Forseth T, Johnsen BO (2000) Latitudinal variation in growth of young brown trout Salmo trutta. J Anim Ecol 69:1010-1020

Katano O, Iguchi K (1996) Individual differences in territory and growth of ayu, Plecoglossus altivelis (Osmeridae). Can J Zool 74:2170-2177

Katano O, Hakoyama H, Matsuzaki SS (2015) Japanese inland fisheries and aquaculture: status and trends. In: Craig JF (ed) Freshwater fisheries ecology. Wiley-Blackwell, Oxford, p 231-240

Kawajiri M, Yamahira K (2011) Ontogenetic variation in fin ray segmentation between latitudinal populations of the medaka, Oryzias latipes. Environ Biol Fishes 92:285-293

Kishino T (2004) Study on the early life history of Ryukyuayu Plecoglossus altivelis ryukyuensis in Amami-oshima Island, southern Japan. PhD dissertation, Kagoshima University

Kishino T (2009) Early life history of Ryukyu-ayu Plecoglossus altivelis ryukyuensis inhabiting in Amami-oshima Island, southern Japan. Kaiyo To Seibutsu 31:388-394 (in Japanese with English Abstract)

Kokita T (2003) Potential latitudinal variation in egg size and number of a geographically widespread reef fish, revealed by common-environment experiments. Mar Biol 143:593-601 
Kooijman SALM (2000) Dynamic energy and mass budgets in biological systems. Cambridge University Press, Cambridge

Kusuda R (1963) An ecological study of the anadromous 'ayu,' Plecoglossus altivelis T. et S.-II. Seasonal variation in the composition of the anadromous ayu schools in the River Okumo, Kyoto. Bull Jpn Soc Sci Fish 29:822-827 (in Japanese with English Abstract)

McDowall RM (2008) Jordan's and other ecogeographical rules, and the vertebral number in fishes. J Biogeogr 35: 501-508

Metcalfe NB, Thorpe JE (1990) Determinants of geographical variation in the age of seaward-migrating salmon, Salmo salar. J Anim Ecol 59:135-145

Murase I, Kawakami T, Iguchi K (2018) Variation in growth performance of Ryukyu-ayu, Plecoglossus altivelis ryukyuensis, inferred from otolith analysis. Ichthyol Res 65: 482-487

Neuheimer AB, MacKenzie BR (2014) Explaining life history variation in a changing climate across a species' range. Ecology 95:3364-3375

Nishida M, Sawashi Y (1987) Geographic differences in the number of longitudinal scales of the ayu Plecoglossus altivelis. Bull Jpn Soc Sci Fish 53:2089

Otake T (2006) Early life history of ayu in coastal waters. Bull Fish Res Agency Jpn Suppl 5:179-185 (in Japanese with English Abstract)

Otake T, Uchida K (1998) Application of otolith microchemistry for distinguishing between amphidromous and nonamphidromous stocked ayu, Plecoglossus altivelis. Fish Sci 64:517-521

Ruppert D, Wand MP, Carroll RJ (2003) Semiparametric regression. Cambridge series in statistical and probabilistic mathematics. Cambridge University Press, Cambridge

Senta T (1967) Ecological study on the larval ayu, Plecoglossus altivelis Temmink et Schlegel, in the neighbouring waters to the mouth of the river with an estuary dam. Research report of the Kisosansen Survey Team 3: 93-111 (in Japanese)

Shiraishi Y, Suzuki N (1962) The spawning activity of ayufish, Plecoglossus altivelis. Bull Freshw Fish Res Lab 12: 83-107 (in Japanese with English Abstract)

Shiraishi Y, Takeda T (1961) The influence of photoperiodicity on the maturation of ayu-fish, Plecoglossus altivelis. Bull Freshw Fish Res Lab 11:69-81 (in Japanese with English Abstract)

Editorial responsibility: Myron Peck,

Hamburg, Germany
Sibly RM, Atkinson D (1994) How rearing temperature affects optimal adult size in ectotherms. Funct Ecol 8: 486-493

Tago Y (2004) Relationship between body size of ayu migrating up rivers flowing into Toyama Bay and water temperature. Suisan Zoshoku 52:315-323 (in Japanese with English Abstract)

Takahashi I (2004) Study on the early life history of ayu in the Shimanto Estuary, Japan. Bull Mar Sci Fish Kochi Univ 23:113-173

Takeshima H, Iguchi K, Hashiguchi Y, Nishida M (2016) Using dense locality sampling resolves the subtle genetic population structure of the dispersive fish species Plecoglossus altivelis. Mol Ecol 25:3048-3064

* Trip EDL, Clements KD, Raubenheimer D, Choat JH (2014) Temperature-related variation in growth rate, size, maturation and life span in a marine herbivorous fish over a latitudinal gradient. J Anim Ecol 83:866-875

Tsukamoto K, Kajihara T (1987) Age determination of ayu with otolith. Bull Jpn Soc Sci Fish 53:1985-1997

*Uchida K, Tsukamoto K, Kajihara T (1990) Effects of environmental factors on jumping behavior of the juvenile ayu Plecoglossus altivelis with special reference to their upstream migration. Bull Jpn Soc Sci Fish 56:1393-1399

Valiente AG, Juanes F, Garcia-Vazquez E (2005) Reproductive strategies explain genetic diversity in Atlantic salmon, Salmo salar. Environ Biol Fishes 74:323-334

* Vøllestad LA (1992) Geographic variation in age and length at metamorphosis of maturing European eel: environmental effects and phenotypic plasticity. J Anim Ecol 61: 41-48

Yamaguchi A, Matsuno K, Abe Y, Arima D, Imai I (2017) Latitudinal variations in the abundance, biomass, taxonomic composition and estimated production of epipelagic mesozooplankton along the $155^{\circ} \mathrm{E}$ longitude in the western North Pacific during spring. Prog Oceanogr 150: 13-19

*Yamahira K, Kawajiri M, Takeshi K, Irie T (2007) Inter- and intrapopulation variation in thermal reaction norms for growth rate: evolution of latitudinal compensation in ectotherms with a genetic constraint. Evolution 61:1577-1589

* Yamamoto T, Mito Y, Yamada Y, Nozaki K, Yoshitsuru Y, Nakata Y, Nimi K (2008) Relationship between distribution of larvae and juveniles of ayu Plecoglossus altivelis altivelis in the sea around Yahagi Estuary (western part of Mikawa Bay), and sediment quality. Bull Jpn Soc Sci Fish 74:841-848 (in Japanese with English Abstract)

Submitted: November 5, 2018; Accepted: June 4, 2019

Proofs received from author(s): July 29, 2019 